\title{
Strategy and numerical modelling of a vehicle seat with a lightweight sandwich design for large-scale production
}

\author{
Song Ren ${ }^{1}$, Kay Schäfer ${ }^{2)}$, Daisy Nestler ${ }^{2)}$, Dominik Krumm $^{3)}$, Stephan Odenwald ${ }^{3)}$, Lothar $\mathrm{Krol}^{4)}$, \\ Marc Fleischmann ${ }^{5)}$ \\ 1) Department of Lightweight Structures and Polymer Technology, song.ren@mb.tu-chemnitz.de, \\ Chemnitz University of Technology, Reichenhainer Straße 31/33, 09126 Chemnitz, Germany \\ 2) Department of Lightweight Structures and Polymer Technology, tkv@mb.tu-chemnitz.de, \\ Chemnitz University of Technology, Reichenhainer Straße 31/33, 09126 Chemnitz, Germany \\ 3) Department of Sports Equipment \& Technology, frage-an-sgt@mb.tu-chemnitz.de, Chemnitz \\ University of Technology, Reichenhainer Straße 70, 09126 Chemnitz, Germany \\ 4) Department of Lightweight Structures and Polymer Technology, slk@mb.tu-chemnitz.de, \\ Chemnitz University of Technology, Reichenhainer Straße 31/33, 09126 Chemnitz, Germany \\ 5) Professorship Textile Technologies, marc.fleischmann@mb.tu-chemnitz.de, Chemnitz University \\ of Technology, Reichenhainer Straße 31/33, 09126 Chemnitz, Germany
}

\section{Keywords}

Finite Element Analysis, Large-scale Production, Lightweight, Sandwich Structure, Vehicle Front Seat.

\begin{abstract}
A lightweight vehicle front seat with a sandwich structure, which consists of skin layers made of glass fibre-reinforced thermoplastic prepregs and a core consisting of a warp knitted spacer fabric filled with polyurethane foam, was developed. The strength test simulations of the seat structure were performed using a Finite Element Analysis approach. The results validate the new sandwich design of the vehicle seat with its adequate strength under a static load. With the innovative lightweight design, the mass of the seat was reduced up to $57 \%$ in comparison to the reference seat from conventional mass production. In addition, a manufacturing process was advised for a large-scale production of the lightweight design within one workstation.
\end{abstract}

\section{Introduction}

The seat is one of the fundamental points of interface between a vehicle and its occupant. The manufacturing of a seat is subjected to a complex set of criteria with respect to driving safety and comfort [1]. It usually consists of a mix of lighter materials such as foam, a spring core or lightweight steel alloy and a light metal sheet. For example, the front seat made of metal and foam of the city car "VW up!" weighs about $15 \mathrm{~kg}$, the lightweight composite materials have a great potential to reduce its weight.

Researchers have been seeking various ways to reduce cost and weight of the seat structure in order to improve fuel efficiency and cost competitiveness, without losses in safety and comfort characteristics. Lahr and Mitschang [2] developed a composite car seat with a sandwich structure, consisting of thermoplastic prepregs as skin layers and a foam core. They were able to shape the whole seat in a tempered press. Recent researches focus on improving this concept with the development of new lightweight materials.

- Glass fibre-reinforced polypropylene (GF-PP) prepregs, applying OLU-Preg® technology, are well drapable for complex cavities and suitable to be pressed directly [3].

- Polyurethane (PUR) foam has a very high flowability in the production process, which can fill complex interspaces between the sandwich shells precisely. [4]

- Warp knitted spacer fabrics (3D textiles) consist of two woven layers as covers, which are connected by monofilaments, with a typical thickness of $15 \mathrm{~mm}$ to $55 \mathrm{~mm}$ [5]. Because of their 
good properties in elasticity of compression, air permeability, heat damping and recyclability, 3D textiles are applied in many fields such as in seat cushions or mattresses instead of conventional polyurethane. Innovative fibre-reinforced sandwich cores with 3D textiles have already been produced by current researches [4-6].

In this study, a vehicle front seat with lightweight components was designed and subsequently a Finite Element Analysis (FEA) was carried out to predict strength failure. The results of the numerical simulation offer a reference to an impact test and show further improvements in the seat structure.

\section{Strategy}

The sandwich structure, i.e. a double-shell structure (Figure 1), can be designed more freely to match different body dimensions individually with an inner shell, while an outer shell is designed to suit the requirements in strength and ensure the mounting to a vehicle. It is also expected that the optimised energy absorption of the seat with a sandwich structure improves comfort and safety for occupants. A construction of the inner shell is based on the city car "VW up!" considering ergonomic and comfort requirements of occupants. In this design, the seat shell has mainly a flat-area shape without any reinforced structures so that it can easily be produced within one pressing process. Each inner and outer shell has a thickness of $2 \mathrm{~mm}$. A sandwich core fills the cavity between the inner and the outer shells, the thickness can be variably adjusted from $4 \mathrm{~mm}$ at the border to about $50 \mathrm{~mm}$ at the transition area between seat back and cushion.

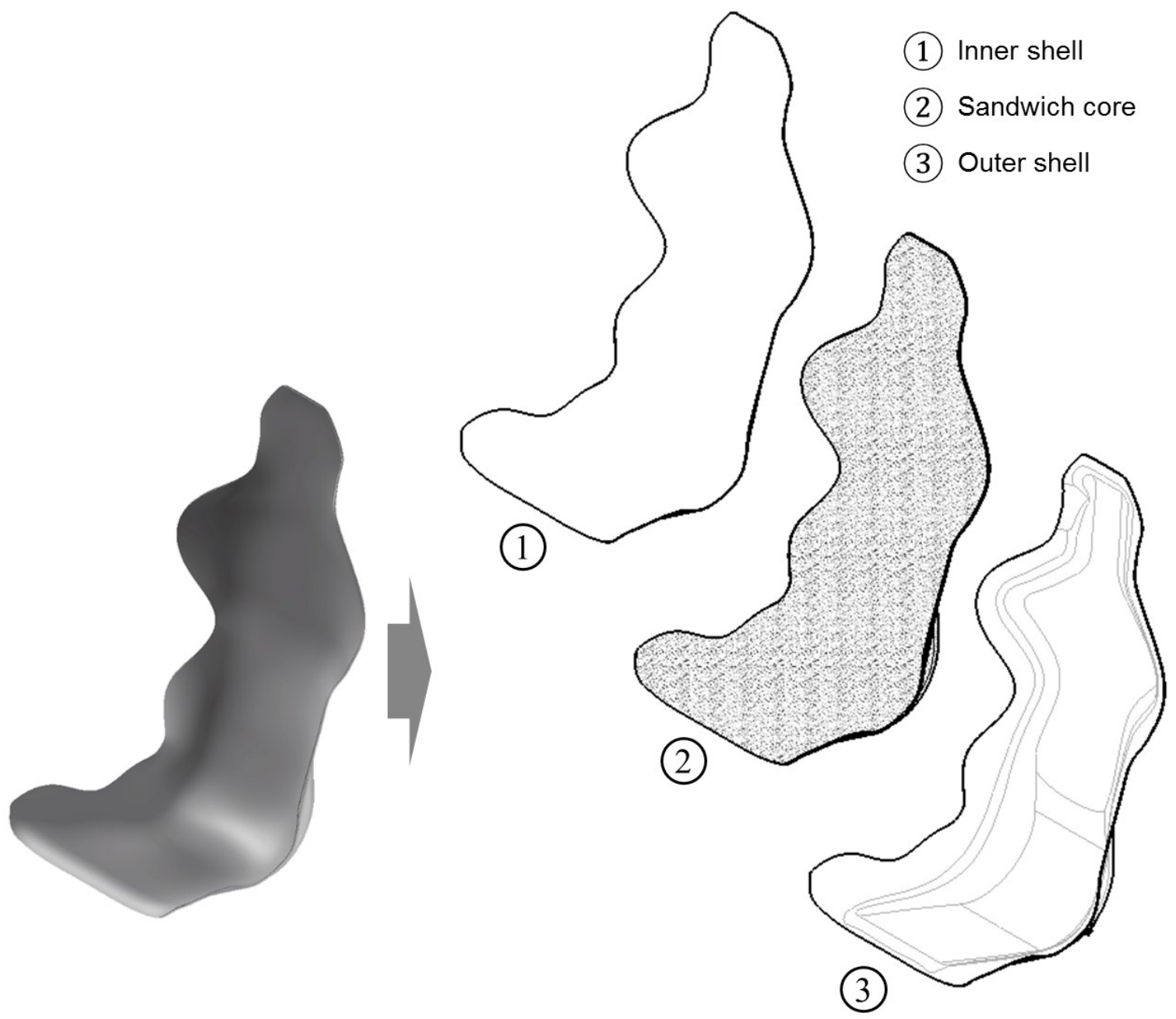

Figure 1: Design of a sandwich seat in an exploded view 


\section{Material and Modelling}

\subsection{Material}

Initially, a standard load case is analysed in a test model so that suitable materials with enhanced constructions can be implemented. The load case is designed under European crashworthiness regulation "ECE R 17" of the United Nations Economic Commission for Europe (UNECE), which is a uniform system of regulations for vehicle designs to facilitate international trade defining a strength test (Figure 2 left). On the upper part of the backrest, a rearward longitudinal force is applied to the back of the dummy yielding a torque of $530 \mathrm{~N} \cdot \mathrm{m}$ around the seating reference point $(R)$. The point $R$ is a design point defined by the vehicle manufacturer for each seating position, which is the pivot centre of the torso and thigh with respect to the three-dimensional reference system [1].
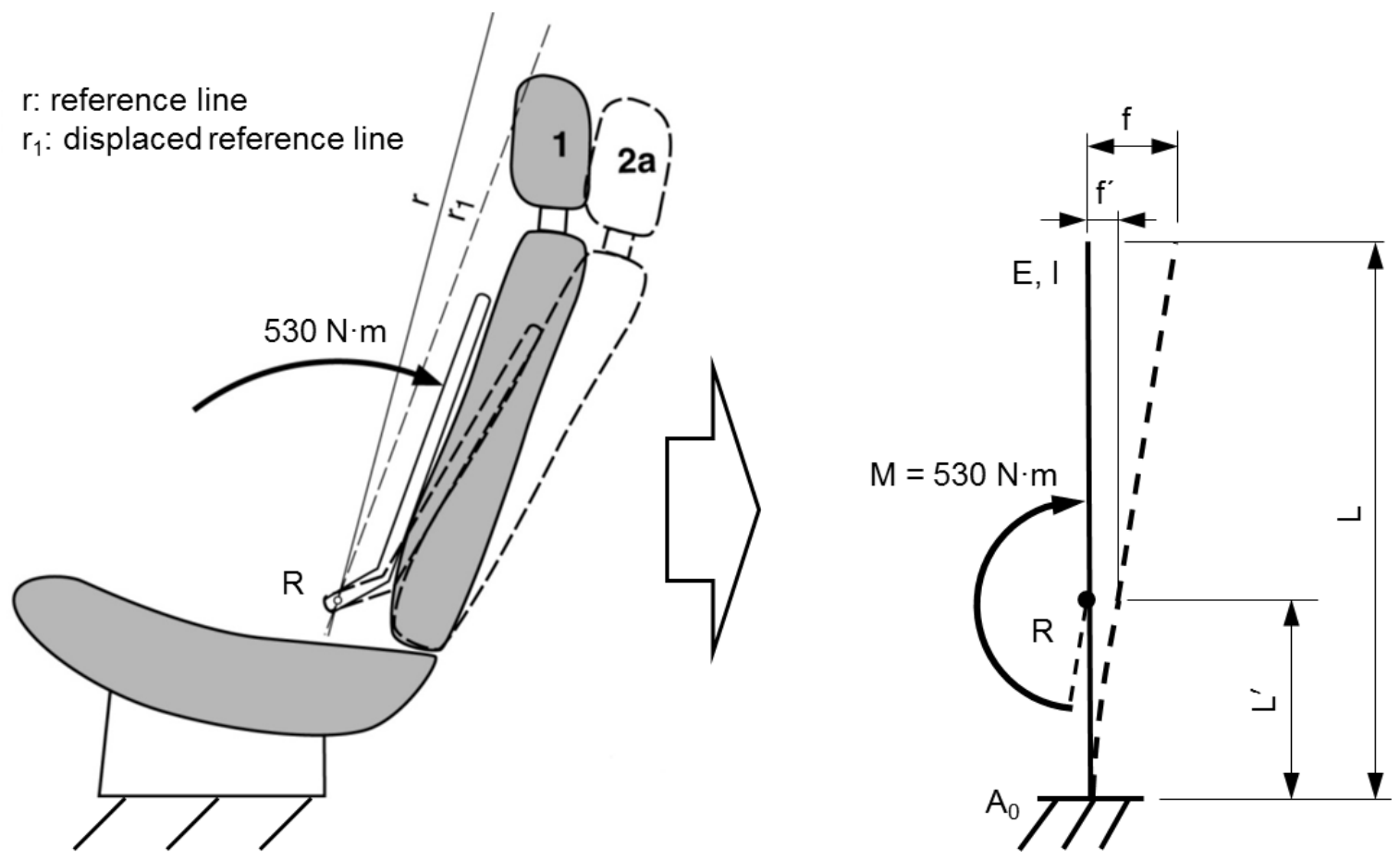

Figure 2: Test of strength of the seat back [1] and simplified beam model

This load case was simplified with a beam model to extract the Young's modulus E (Figure 2 right), in which the model is fixed at the point $A_{0}$ and a torque moment $M$ is applied on the beam about the point $R$. The distance $L^{\prime}$ between $A_{0}$ and R equals $150 \mathrm{~mm}$. According to "ECE R 17" [1], a maximum backward displacement of the car seat must be less than $102 \mathrm{~mm}$. In this case, maximum backward displacement occurs at the top end of the beam. Since the area of the seat is relatively flat and the cross section of the seat back is variable, the following assumptions have been made: The cross section of the beam model is a rectangle with a constant dimension of $b \times h$. The minimum cross section between $A_{0}$ and $R$ was applied where the measured width $b$ is $390 \mathrm{~mm}$ and the thickness $\mathrm{h}$ is $8 \mathrm{~mm}$.

According to the equations in [7], the deflection at point $R$ is:

$$
\begin{aligned}
& f^{\prime}=\frac{M L^{\prime 2}}{2 E I} \\
& \text { with the second moment of area } I=\frac{b h^{3}}{12}
\end{aligned}
$$

and maximum backward displacement:

$$
f=\frac{L}{L^{\prime}} \cdot f^{\prime}<102 \mathrm{~mm}
$$


The Young's modulus of the applied material in the longitudinal direction should be higher than $16 \mathrm{GPa}$. This value helps to choose a proper material for the vehicle seat. However, the real cross section is variable and the applied values of $b$ and $h$ are at a minimum. Therefore, it is necessary to calculate the maximum backward displacement by using FEA for the selected material. In addition, no comments were made for a dynamic load type in "ECE R 17" [1]. For this reason, only a static FEA was implemented in this work.

As a material for the skin layers, the thermoplastic prepreg OLU-Preg ${ }^{\circledR}$ (Table 1) from SKM GmbH Moers was selected, which is a commercially available semi-finished product of GF-PP composite sheets with a fibre content of $41 \%$ and a Young's modulus of $17.5 \mathrm{GPa}$ [3]. In the design of the sandwich structure, the layups of the top (inner) layer and the bottom (outer) layer were symmetrically constructed with 10 plies each with a thickness of $0.2 \mathrm{~mm}$. The fibre orientations $\alpha$ of each ply are shown in Figure 3.

Table 1 Mechanical properties of the thermoplastic prepreg OLU-Preg ${ }^{\circledR}$ [3]

\begin{tabular}{ccccc}
\hline Material & $\begin{array}{c}\text { Density } \\
\left(\mathbf{k g} / \mathbf{m}^{3}\right)\end{array}$ & $\begin{array}{c}\text { Young's modulus } \\
(\mathbf{G P a})\end{array}$ & $\begin{array}{c}\text { Tensile strength } \\
(\mathbf{M P a})\end{array}$ & $\begin{array}{c}\text { Flexural strength } \\
(\mathbf{M P a})\end{array}$ \\
\hline OLU-Preg $^{\circledR}$ & 1800 & 17.5 & 330 & 300 \\
\hline
\end{tabular}

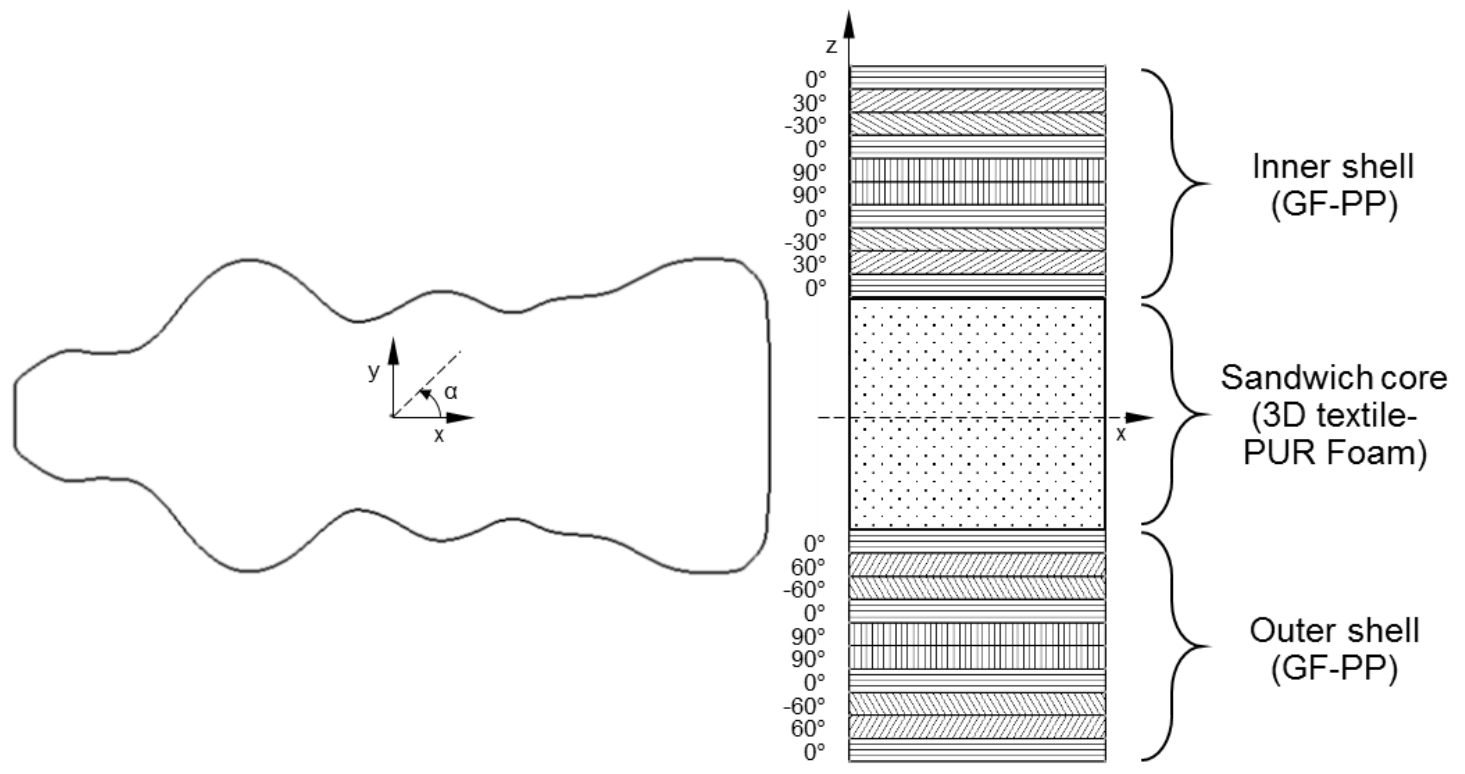

Figure 3: Orientation of fibres in an unfolded view of the seat's inner shell (left) and the design of the total sandwich structure (right)

The sandwich core is a 3D textile-PUR foam composite. This new type of lightweight composite has recently been considered in research and development [4-6]. The compressive stress and energy absorption of this hybrid material was significantly improved compared to neat PUR foams made from polyol and isocyanate by chemical reaction. The mechanical properties of the composite core in Table 2 are experimental results [4].

Table 2: Mechanical properties of 3D textile-PUR foam composite [4]

\begin{tabular}{ccccc}
\hline Material & $\begin{array}{c}\text { Density } \\
\left(\mathbf{k g} / \mathbf{m}^{\mathbf{3}}\right)\end{array}$ & $\begin{array}{c}\text { Bulk modulus } \\
(\mathbf{M P a})\end{array}$ & $\begin{array}{c}\text { Compression strength } \\
(\mathbf{M P a})\end{array}$ & $\begin{array}{c}\text { Flexural strength } \\
(\mathbf{M P a})\end{array}$ \\
\hline $\begin{array}{c}\text { 3D textile-PUR foam } \\
\text { composite }\end{array}$ & 145 & 5.2 & 0.3 & 0.26 \\
\hline
\end{tabular}




\subsection{Modelling}

The FEA was performed in an ANSYS Workbench environment. The inner and outer shells were assumed with the real fibre orientations and the core was considered isotropic. All applied materials were assumed as elastic and their performance was simulated under the load of the mentioned test in "ECE R 17". The position of the point $\mathrm{R}$ was defined in a three-dimensional reference system. A torque moment with the value of $530 \mathrm{~N} \cdot \mathrm{m}$ was applied longitudinally and rearwards to the upper part of the seat back frame around point R. Each laminate part, including the inner and the outer shells, was discretised with quadrilateral dominant shell elements whose average size was set to $2.5 \mathrm{~mm}$. The composite core was discretised with solid elements and the average size of the elements was set to $10 \mathrm{~mm}$.

The inner and the outer shells were joined with the composite core. As the adhesion test between 3D textile-PUR foam composite and OLU-Preg ${ }^{\circledR}$ has not been performed yet, the interface is simplified as a bonded connection (no sliding or separation) in this paper. The joint between the seat and the vehicle interior is also regarded as a bonded connection in order to simplify the FE model (Figure 4) and to accelerate the operation speed.

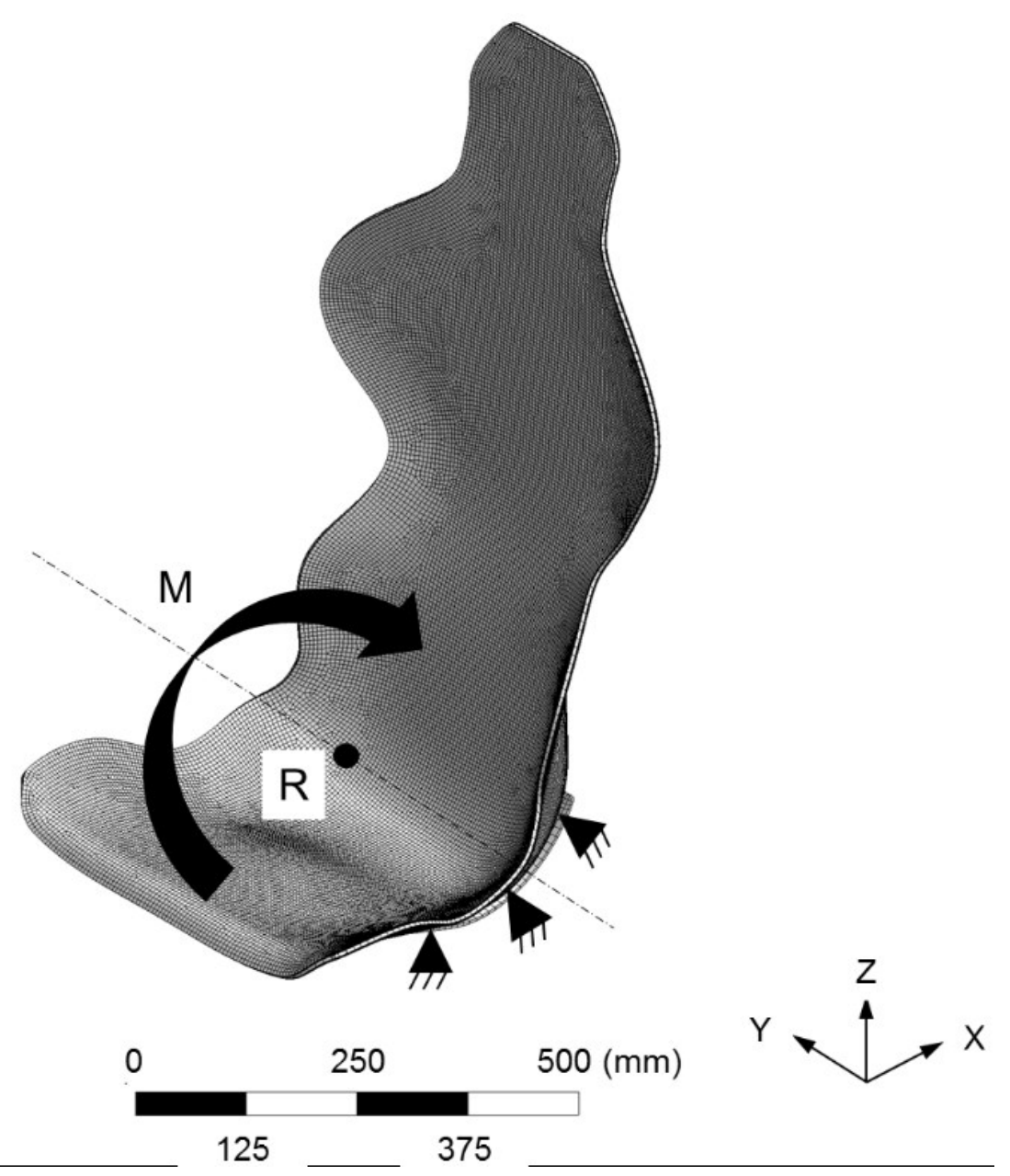

Figure 4: FE model of the sandwich seat with FE mesh and loading condition

After the FE model was established, it was necessary to determine a failure envelope, to verify whether material failures occur under the load defined by "ECE R 17".

First of all, as mentioned in 3.1, the maximum backward displacement of $102 \mathrm{~mm}$ cannot be exceeded. Then, with an application of laminate material, a failure analysis must be implemented. In the case of layered composites with staggered unidirectional plies, the simulation tool "ANSYS Composite PrepPost (ACP)" offers a wide range of failure criteria, including maximum strain, maximum stress, Tsai-Wu, TsaiHill, Hashin, Hoffman, Puck and Cuntze [8], which can be selected upon need in the workbench. The 
outcome of a failure analysis does not only depend on the failure measurement of a single ply but also on the interaction between adjacent plies.

The Inverse Reserve Factor (IRF) [8] is imported with respect to a safety factor 1.5 [9] for fibre-reinforced laminates:

$$
I R F=\frac{1.5 \cdot \text { Applied Load }}{\text { Material Strength }}
$$

The IRF indicates how far one laminate is away from failure state under defined loading case(s). It can be specified for inter-fibre failure, as well as for fibre failure. Failure occurs in the case that the IRF-value is greater than one.

In order to compare the IRF-values with different layups of the skin layers, three reference models (RM) were built (Figure 5). In the model RM-1, the layups of the sandwich seat were applied, where the outer and the inner shell were connected directly without the core. Therefore, the IRF-value of this reference model can also be compared to the sandwich model. The model RM-2 with a (0/90/ \pm 45$)$-laminate structure is similar to an aircraft construction laminate [9], while RM-3 has more fibres in $0^{\circ}$ and $90^{\circ}$ directions. All three reference models were built with OLU-Preg ${ }^{\circledR}$ and have a total thickness of $4 \mathrm{~mm}$. In FEA, the same material property, loading and boundary conditions were carried over from the analysis of the sandwich model.

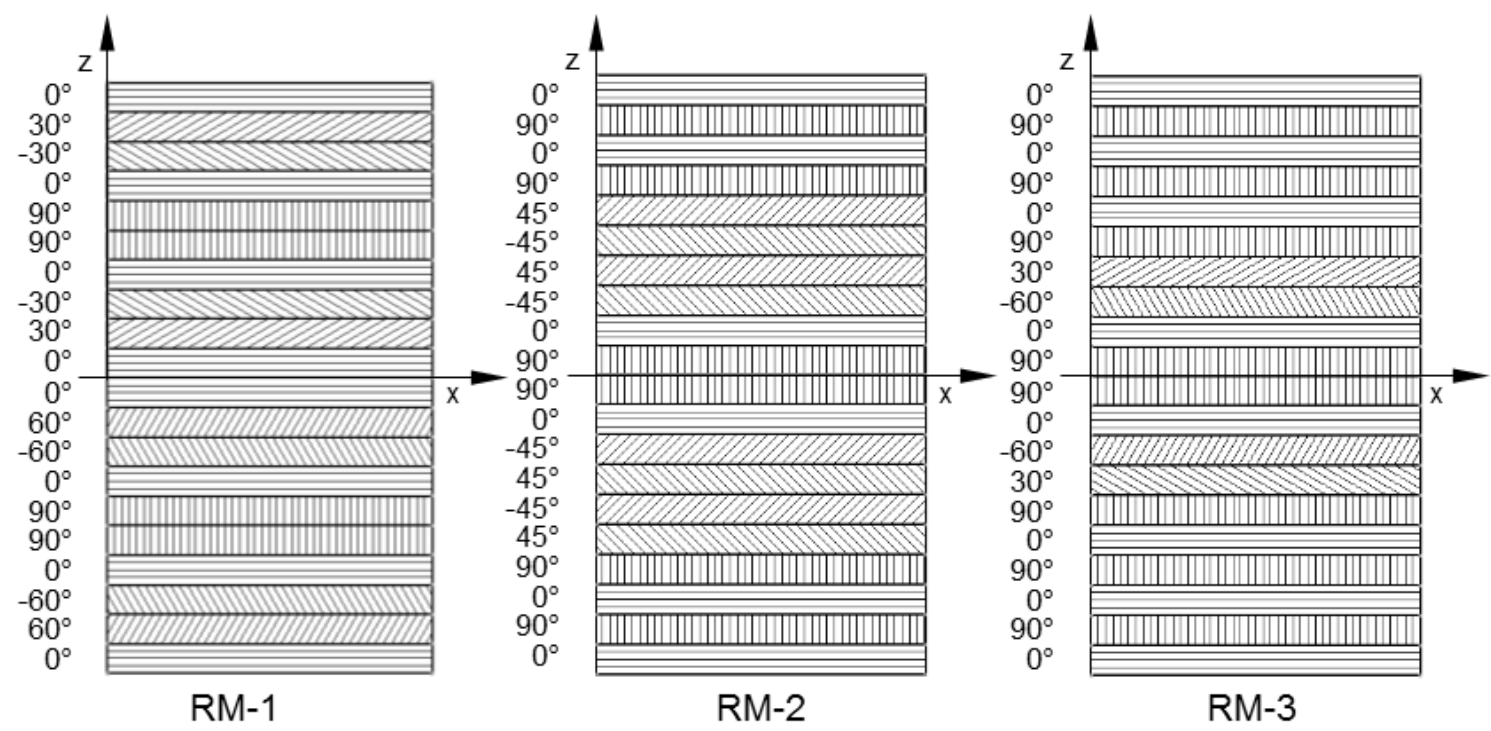

Figure 5: Layups of the laminate in one-shell reference models

\section{Results and discussion}

Figure 6 illustrates the total deformation of the sandwich seat under the defined load. The maximum deformation is located at the top edge of the backrest. With a value of $32.1 \mathrm{~mm}$, the backward deformation does not exceed the permissible value according to "ECE R 17". 
Static-mechanical analysis

Type: Total Deformation

Unit: $\mathrm{mm}$
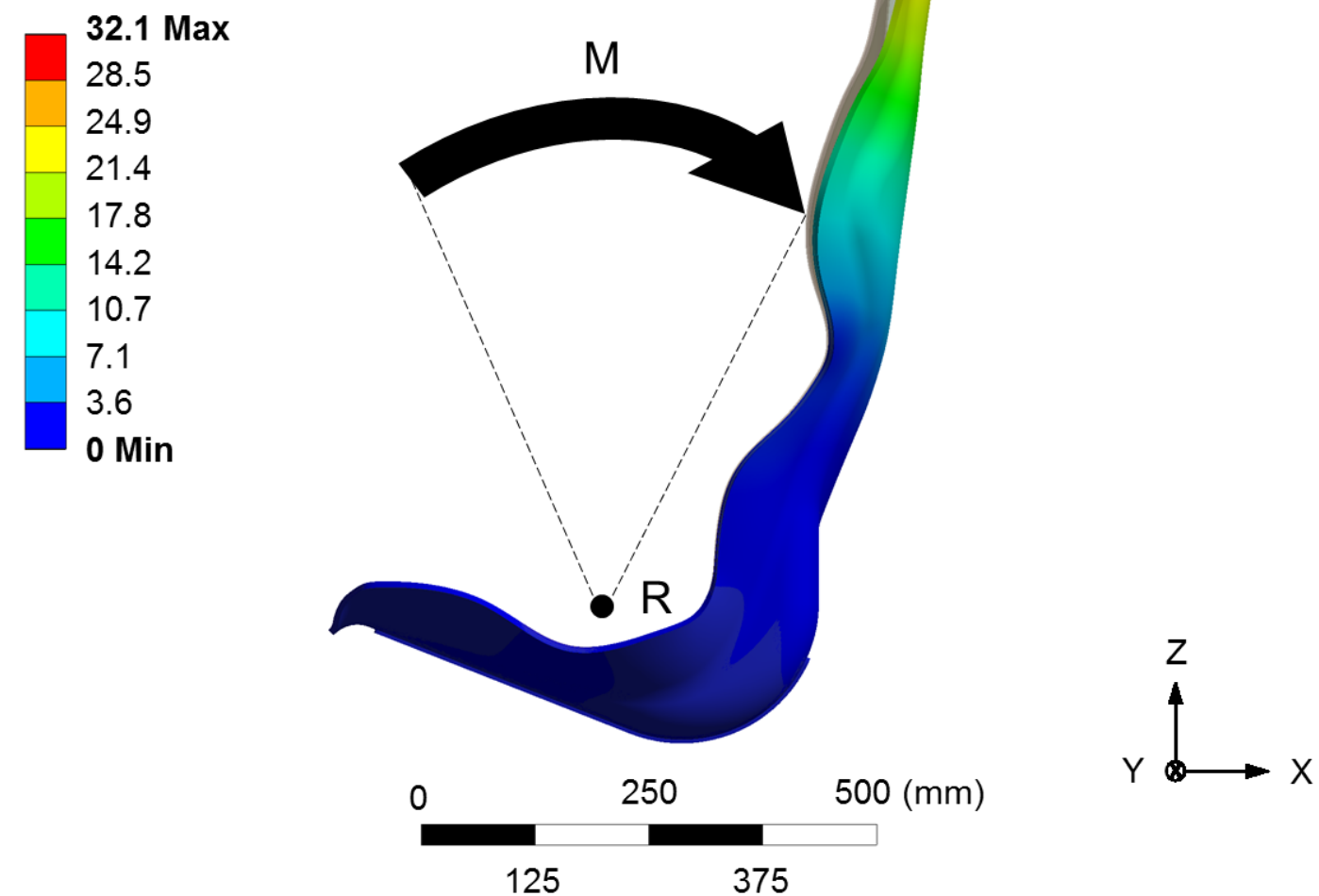

Figure 6: Total deformation of the sandwich seat with a torque of $530 \mathrm{~N} \cdot \mathrm{m}$ around seat reference point $(R)$

The reference models from RM- 1 to RM-3 show many more space deformations, which are nearly three times higher than the sandwich seat model (Table 3). The results of failure analysis were indicated by IRF-values (Table 4). It is visible that no failure occurs for the IRF-values of the inner and outer shells of the sandwich seat model, since the IRF-values are smaller than one. Comparing the layups of the three reference models, there are no significant differences in IRF-values, which means that the laminate construction is not a significant influencing factor in this case.

Table 3: Maximum deformations of the sandwich seat model and three reference models

\begin{tabular}{ccccc}
\hline FE model & Sandwich seat model & RM-1 & RM-2 & RM-3 \\
\hline Deformation $[\mathrm{mm}]$ & 32.1 & 81.1 & 83.1 & 83.3 \\
\hline
\end{tabular}

Table 4 IRF-values of the sandwich seat model and three reference models

\begin{tabular}{ccccc}
\hline FE model & Sandwich seat model & RM-1 & RM-2 & RM-3 \\
\hline \multirow{2}{*}{ IRF-value } & 0.8 (inner shell) & 3.4 & 2.9 & 3.2 \\
\hline
\end{tabular}


With the densities of all the applied materials, the seat mass can be measured in a CATIA V5 environment. The total weight of the sandwich seat is $6.5 \mathrm{~kg}$ without any fasteners like screws, bolts or screw nuts. In comparison to $15 \mathrm{~kg}$ of one front seat of "VW up!", the innovative lightweight seat design saves $8.5 \mathrm{~kg}$, thus reducing $57 \%$ in mass.

\section{Conclusion and outlook}

During this work, a vehicle front seat with a sandwich structure, which saves up to $57 \%$ in weight of the city car "VW up!", was developed. This technology is conveniently transferable to a large-scale production in order to bring a lightweight multi-material design from the latest research to the automobile industry.

Based on the current investigations [2, 10,11], a pressing process with integrated foam injection moulding needs to be developed (Figure 7). Initially, two thermoplastic prepreg sheets need to be preheated at a defined temperature, e.g. OLU-Preg ${ }^{\circledR}$ at about $220{ }^{\circ} \mathrm{C}$ and set into tempered multiinjection moulding tools by a robot. Then the tools would be closed and the inner and the outer shells formed separately. After the forming process is complete, the tools will be opened to bring both shells together into one cavity by means of a swivel plate. After insertion of a 3D textile, the shells will be joined by injected foam and finally removed from the mould.

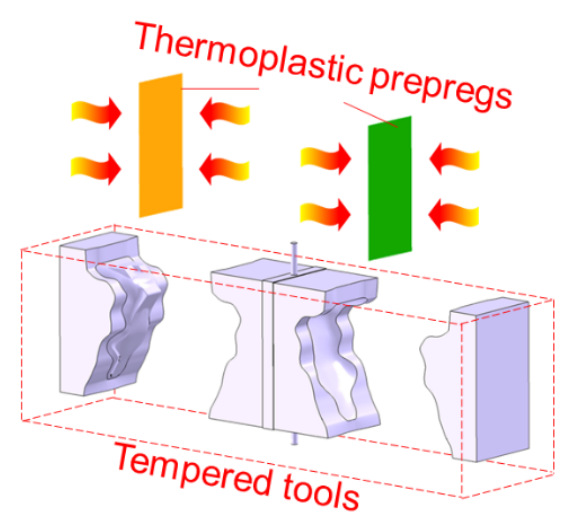

(1) Preheating

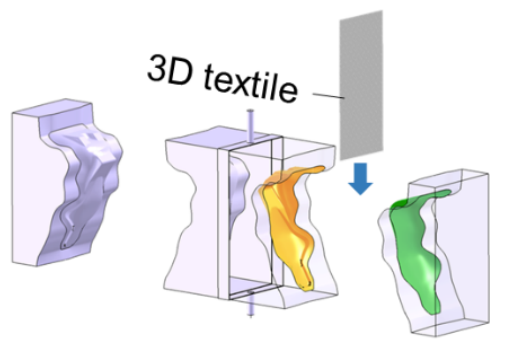

(4) Inserting a 3D textile

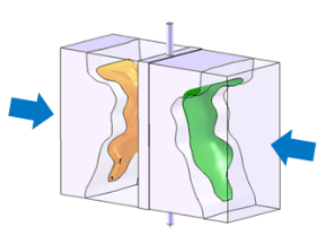

(2) Forming

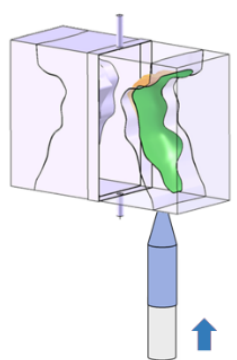

(5) Foam injection moulding
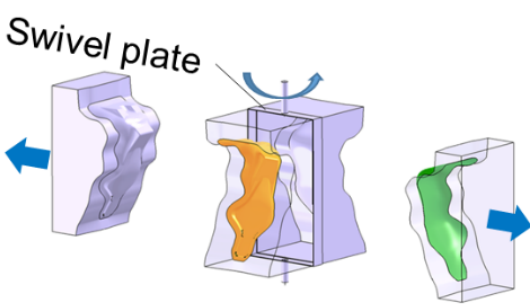

(3) Changing tools

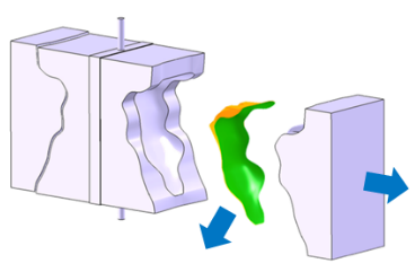

Deforming

Figure 7: Concept of a large-scale production of the sandwich seat

The total cycle time of the processes 1-6 is estimated to be about $15 \mathrm{~min}$. Most of the time is exhausted by preheating the thermoplastic prepregs and by injecting as well as by the curing of the foam. The main forming process 2 should require only a small period of time, i.e. $60 \mathrm{sec}$. The excess materials would be removed by a separate trimming process with a 5-axis milling machine.

In order to investigate layup constructions and implement failure analysis of composite materials, a FE model was developed, which can be used to develop yet another vehicle seat. If necessary, it will 
be rounded with more load cases, such as dynamic or thermal stress. An additional interesting issue for vehicle seat manufacturers is the integration of components like a headrest or a heating system into the seat structure, which will improve the ride comfort for the occupants.

\section{Acknowledgement}

This work was performed within the Federal Cluster of Excellence EXC 1075 "MERGE Technologies for Multifunctional Lightweight Structures". The authors gratefully acknowledge the financial support of the German Research Foundation (DFG).

\section{References}

[1] ECE R 17: Uniform provisions concerning the approval of vehicles with regard to the seats, their anchorages and any head restraints. In: United Nations Economic Commission for Europe, Addendum 16, Regulation No. 17, Revision 5, 2014.

[2] Lahr, R.; Mitschang, P.: Konzeption und Herstellung eines Composite-Autositzes. In: Tagungsband "1. Landshuter Leichtbaukolloquium", Landshut, Deutschland (2003), S. 235-242.

[3] Brunk, N.; Gründig, E.; Helbig, F.; Reinhardt, M.; Scheika, M.; Unger, C.: Schutzrecht DE102012007631 A1: Textile Mehrschicht-Verstärkungsstruktur mit integrierter thermoplastischer Matrix zur Herstellung von umformbaren Faserverbund-Halbzeugstrukturen. SKL Schwergewebekonfektion Lichtenstein $\mathrm{GmbH}, 2012$.

[4] Schäfer, K.; Meier, B.; Anders, S.; Helbig, F.; Kroll, L.: A strengthening bond: Composites made from 3D warp-knitted textiles and polyurethane foam have a considerable reinforcing effect. Kettenwirk-Praxis, 2 (2014), pp. 34-36,.

[5] Dura Brisa, V.J.; Helbig, F.; Kroll, L.: Numerical characterisation of the mechanical behaviour of a vertical spacer yarn in thick warp knitted spacer fabrics. J. of Ind. Text., 45(1) (2014), pp. 101117. doi: $10.1177 / 1528083714523164$

[6] Pan, Y.J.; Lou, C.W.; Hsieh, C.T.; Huang, C.H.; Lin, Z.L.; Li, C.W.; Lin, J.H.: Nonwoven Fabric/Spacer Fabric/Polyurethane Foam Composites: Physical and Mechanical Evaluations. Fibers and Polymers, 17(5) (2016), pp. 789-794. doi: 10.1007/s12221-016-5736-0.

[7] Grote, K.-H.; Feldhusen, J.: Dubbel: Taschenbuch für den Maschinenbau. 22., neubearbeitete und erweiterte Auflage. Berlin, Heidelberg: Springer, 2007.

[8] Seminar documentation of ANSYS Composite PrepPost. Chapter 18-Failure Criteria. (c) CADFEM GmbH 2016.

[9] Schürmann, H.: Konstruieren mit Faser-Kunststoff-Verbunden. 2., bearbeitete und erweiterte Auflage. Berlin, Heidelberg: Springer, 2007.

[10] Stiller, J.; Schäfer, K.; Helbig, F.; Tröltzsch, J.; Nestler, D.; Kroll, L.: Material Selection and Process Configuration for Free-Form, Voluminous and Textile-Based Multi-Material-Design by the Example of a Bucket Seat. Key Eng. Mater., 742 (2017), pp. 302-309. doi: 10.4028/www.scientific.net/KEM.742.302

[11] Roch, A.; Menrath, A.; Huber, T.: Fiber-reinforced thermoplastics as sandwich construction. Kunststoffe international, 10 (2013), pp. 119-124. 